\title{
Limitations to Work-Related Functioning of People with Persistent "Medically Unexplained" Physical Symptoms: A Modified Delphi Study Among Physicians
}

\author{
K. H. N. Weerdesteijn ${ }^{1,2,3} \mathbb{D} \cdot$ F. G. Schaafsma ${ }^{1,2} \cdot$ A. J. van der Beek ${ }^{1,2} \cdot$ \\ J. R. Anema ${ }^{1,2}$
}

Published online: 19 October 2016

(C) The Author(s) 2016. This article is published with open access at Springerlink.com

\begin{abstract}
Purpose The purpose of this study was to obtain consensus among physicians of several medical specialties on the level of limitations to work-related functioning of people with persistent "medically unexplained" physical symptoms (PPS). Methods A modified Delphi study was conducted with 15 physicians of five different medical specialties. The study involved two email rounds and one meeting. In each round, the physicians prioritized the level of limitations in 78 work-related functioning items for four different PPS cases. These items were based on the Dutch Functional Ability List, national guidelines and scientific literature regarding the International Classification of Functioning. Results In all four cases, the physicians reached consensus on the level of limitations to work-related functioning in 49 items. The physicians reported the highest number and level of limitations for PPS of the back and lower extremities, but they reported hardly any limitations for PPS of the abdomen and genitals. For PPS of the head, they reported mainly limitations to personal and
\end{abstract}

Electronic supplementary material The online version of this article (doi:10.1007/s10926-016-9674-x) contains supplementary material, which is available to authorized users.

\section{K. H. N. Weerdesteijn}

k.weerdesteijn@vumc.nl

1 Department of Public and Occupational Health, The EMGO+ Institute for Health and Care Research, VU University Medical Center (VUmc), van der Boechorststraat 7, 1081 BT Amsterdam, The Netherlands

2 Research Center for Insurance Medicine (KCVG), AMCUMCG-UWV-VUmc, PO Box 7057, 1007 MB Amsterdam, The Netherlands

3 Department of Social Medical Affairs (SMZ), Dutch Social Security Agency (UWV), La Guardiaweg 94-114, 1043 DL Amsterdam, The Netherlands social functioning; for PPS of the neck, back and upper or lower extremities, they reported mainly limitations to dynamic movements and static postures. The physicians could not reach consensus on limitations in the category of working hours. Conclusion Physicians reached consensus on the level of limitations in a substantial part of workrelated functioning items for PPS. There was a difference in the number and severity of limitations between different cases of PPS. The assessment of functioning seems to be based more on the specific impairment than on the disease.

Keywords Medically unexplained symptoms · Insurance, disability assessment · Functional limitations · Delphi technique $\cdot$ Persistent physical symptoms

\section{Introduction}

The most commonly used term for persistent physical symptoms that, after appropriate medical examination, lack an underlying pathological cause, and therefore cannot be fully explained by a defined organic disease, is medically unexplained physical symptoms (MUPS) [1]. Despite the term "medically unexplained", there is more and more evidence that these physical symptoms might be explained through underlying processes and mechanism. Therefore, and on behalf of the preferences of patients, we chose to use the term Persistent "Medically Unexplained" Physical Symptoms (in short PPS) for these type of symptoms [2, 3]. PPS are common worldwide, compromising up to $50 \%$ of all consultations in curative health care $[4,5]$. Most of these symptoms are self-limiting or recover within a year after some form of therapy, but for about $20-30 \%$ of people with PPS the symptoms persist for a longer period of time $[6,7]$. Those people often have multiple, severe 
complaints and feel high physical distress, which mostly leads to social dysfunction [8]. In addition, the physical distress is associated with significant occupational dysfunction, long duration of sick leave, and work disability $[9,10]$. For example, Hoedeman et al. reported a prevalence of $15 \%$ of severe PPS in employees on long-term sick leave [11], and those employees may be eligible for a work disability benefit $[12,13]$. In several European countries, at least 5-8\% of all new work disability benefits are awarded to people with PPS [14, 15].

The process of deciding on a claimant's eligibility for a work disability benefit varies between countries, but what usually plays a crucial role in the assessment is the underlying cause of the complaints and the interpretation of limitations to work-related functioning [16, 17]. For the interpretation of limitations to work-related functioning, physicians have to translate medical findings and complaints to functional abilities and work disabilities [18, 19]. The outcome of such work disability assessments is not only essential for the eligibility of a work disability benefit, but also for the advice physicians give about recovery and participation opportunities, long-term prognosis, and treatment options $[17,20]$. As differences in advice may form an unnecessary obstacle in the recovery and return-towork process [12, 21], it is important there is agreement on the limitations to work-related functioning between physicians in various settings, such as insurance medicine, occupational medicine and curative health care [22, 23].

In cases of PPS, many physicians find it difficult to translate the complaints and dysfunction to limitations to work-related functioning because of the lack of objective medical findings [24, 25]. Complaints mostly do not correlate with physicians' objective findings, nor with the work capacity rated by physicians [26]. Moreover, studies have shown that physicians of different medical specialties, and physicians from several countries, can differ in their appraisal of work ability in people with PPS [27, 28]. This emphasizes the need for more knowledge on how to assess abilities and disabilities in work for this target group, and to limit disagreements in determining eligibility for sick leave or a work disability benefit. To support physicians in these assessments, and to prevent differences in appraisals, several studies have provided recommendations and advices on standardized procedures for a work disability assessment $[29,30]$. However, these recommendations are not specific in their formulation, and do not provide particular recommendations on how to translate complaints to limitations to work-related functioning.

Despite the high prevalence of people with PPS, and the high number of these people claiming a work disability benefit, there is still limited evidence for a uniform policy in the work disability assessment of people with PPS. Therefore, it is important to reach consensus between physicians of different medical specialties. The aim of this study was to reach consensus on the level of functional limitations related to work of people with PPS among physicians of several medical disciplines.

\section{Methods}

This study used a modified Delphi technique by combining the Delphi technique and the nominal group technique [31]. These techniques are the most commonly accepted consensus methods in health care services in cases where the research evidence is incomplete, unobtainable or conflicting $[32,33]$. The Delphi technique is a decision-making multistage technique among anonymous experts, whereas the nominal group technique uses structured meetings with face-to-face contact $[32,33]$. Both methods aim to obtain consensus among experts on a given issue by ranking a list of items in several rounds [32,33]. Previous research has used several modifications and combinations of these techniques as well $[34,35]$.

The combined Delphi technique and nominal group technique in this study was used to obtain multidisciplinary consensus among physicians on limitations in work-related functioning items for people with PPS. The entire process consisted of a preliminary round, two email rounds according to the criteria of the Delphi technique, and one meeting using the nominal group technique. An overview of the study design is presented in Fig. 1. The study was conducted between January and September 2015.

\section{Preliminary Round}

To help provide a guide and reference points for the physicians in this study we used case vignettes of common PPS. For pragmatic reasons we chose a maximum of four case vignettes, and based the type of PPS on their prevalence according to the literature, and on the numbers of the Dutch Social Security Agency (SSA) [36, 37]. These are PPS of the head, neck and upper extremities, abdomen and/ or genitals, and the back and lower extremities (Appendix A). For each type of PPS we searched the database of the SSA. We chose four real cases as case vignettes. All cases provided adequate and clear information about the health complaints, the treatment and the guidance in the return-towork process up till now.

The Functional Ability List (FAL) [38] was used, in combination with a part of the International Classification of Functioning (ICF) [20], to develop a list of work-related functioning items. The FAL is a standardized format list of 106 functioning items, used by insurance physicians (IPs) in the Netherlands, to assess limitations and disabilities that may be important to functioning in work [38]. The FAL is 


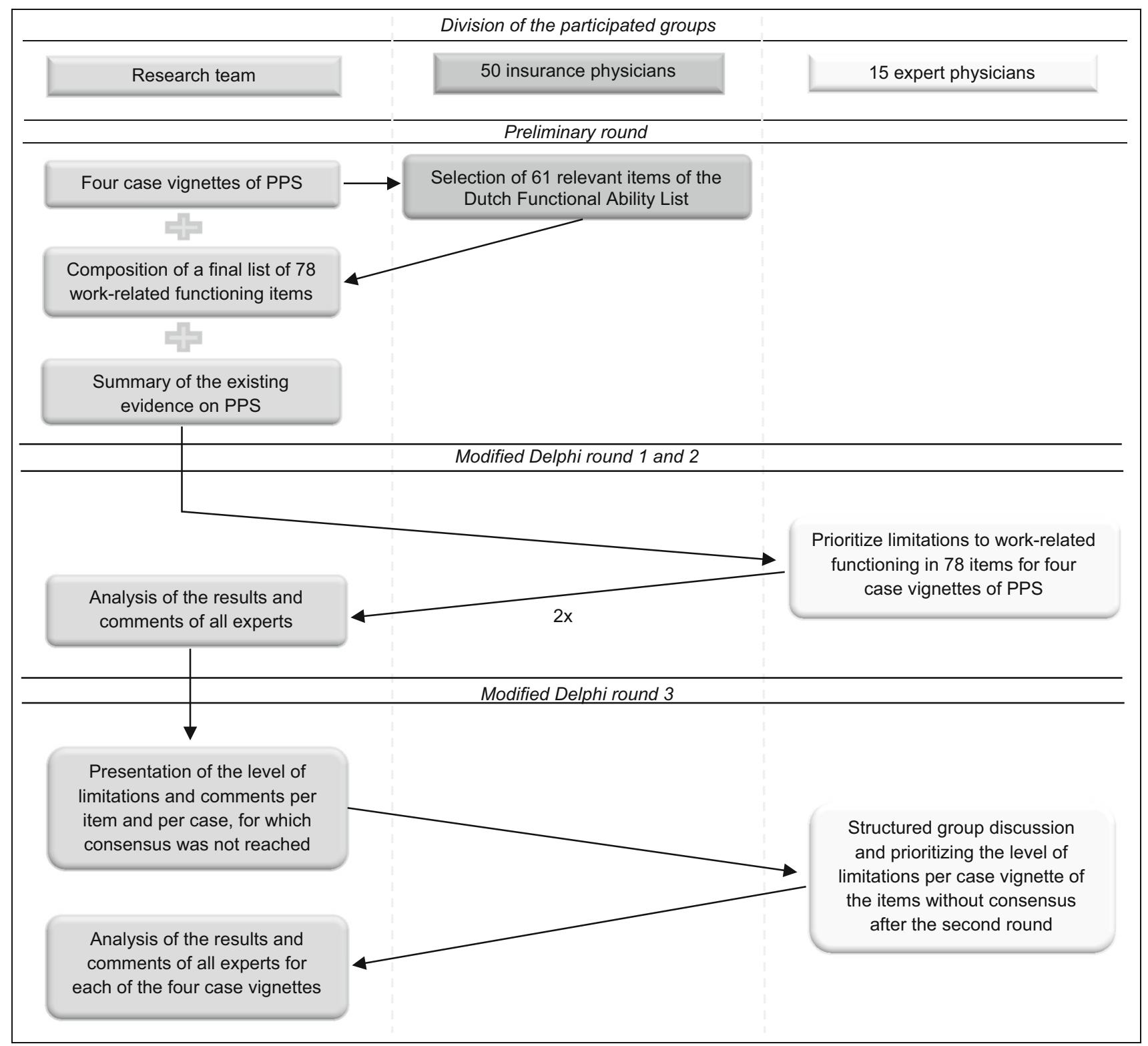

Fig. 1 Study design

comparable to the ICF, but with more detailed items. The items of the FAL are categorized into six domains: personal functioning (30 items), social functioning (17 items), dynamic movements (31 items), static postures (11 items), adjusting to environment (13 items), and working hours and time (4 items). More than two-third of the items have a dichotomous scoring option; the presence or absence of a specific functional limitation. Nearly one-third has three up to five ordinal scoring options providing a range of functional limitations [38].

In order to develop a design list of work-related functioning items for this modified Delphi study, a group of 50 IPs were asked to select which items of the FAL can give possible limitations to work-related functioning in the four different case vignettes of PPS. We then asked these IPs to recommend the medical specialty fields of physicians who should participate in this study. This was done during a meeting in which PPS, in general and in relation to work disability, were discussed between the IPs and the researcher (KW). The IPs selected 61 relevant items from the FAL, and the researchers compared this list of items with the scientific literature regarding the ICF [39-41], and with national guidelines [42] about limitations and functioning of people with PPS. As a result, 17 additional possible relevant items of work-related functioning with PPS were added to the list of 61 items. This addition resulted in a final list of 78 work-related functioning items. 


\section{Expert Panel Selection}

Based on the recommendations of the 50 IPs, this study used physicians of five medical specialties highly involved in the treatment or guidance of patients with PPS in the return-to-work process. For a structured meeting, a maximum of 20 persons is advised [31-33]. We invited 18 physicians to participate in our study, anticipating that at least $80 \%$ would agree. The invited physicians were all considered experts in PPS because they had sufficient professional experience in dealing with PPS in their own daily practice. The resulting expert panel $(n=15)$ consisted of three IPs, three occupational physicians, three general practitioners, three psychiatrists, and three rehabilitation physicians.

\section{The Modified Delphi Technique}

Rounds 1 and 2 In the first round, the experts received descriptions of the four case vignettes and a summary of the existing evidence on PPS created by the researchers. In addition, they received the final list of 78 work-related functioning items, with a directory on how these items should be evaluated. The experts were asked to report any potential limitations in these items per case vignette, based on their expertise and the available literature. All experts were asked to do this independently, but they could give comments or ask questions via email. Figure 2 shows an example of one of the items to be scored.

After the first round, the researchers processed and calculated the scoring of each expert, and calculated the degree of consensus in each item per case vignette. All items with $\geq 75 \%$ agreement on the level of limitations were accepted without further rating or discussion. In the second round, the level of scores per item in which no consensus was reached, together with a summary of the comments from the experts in the first round, were sent back to the experts via email. The experts were again asked to rate these items per case vignette. After this second email round, the researchers processed and calculated the results of the reported limitations in the same way as after the first round.

Round 3 In the third round, a meeting was arranged for all experts. During this meeting, the researchers explained once more the objective of the study, the results so far, and what the procedures of the nominal group technique entailed. After this introduction, the researchers graphically presented the level of limitations per item and per case vignette for which consensus was not yet reached. In addition, they presented the new comments from the second round. The experts were invited to discuss all these remaining items per case vignette. With the nominal group technique, all experts had the opportunity to clarify and to

\section{Bending}

Definition:

Bending the upper body forward from a standing position and return back to the standing position shortly after.

\section{Interpretation:}

The dynamic load of bending concerns a few degrees of bending, normally no more than 90 degrees. When bending, the bended position does not take more than a few seconds. Bending can be necessary to increase the maximal effective personal reaching distance; to touch an object beneath hip height, to pick something up, to put something down, or to manipulate something. The angle of bending will be appraised by drawing a notion line from the hip joint to the shoulder joint. The angle of this line in combination with the lead line is the bending angle.

\section{Ability score:}

0 . Normal: is able to bend over an angle of 90 degrees (able to pick up a piece of paper from the ground)

1. Limited: is able to bend over a maximum angle of 60 degrees (able to pick up a bag from the ground)

2. Highly limited: is able to bend over a maximum angle of 45 degrees (able to pick up something from a chair)

\begin{tabular}{|c|c|c|}
\hline & Ability score & Comments \\
\hline Case 1: PPS of the head & & \\
\hline Case 2: PPS of the neck and upper extremities & & \\
\hline Case 3: PPS of the abdomen and/or genitals & & \\
\hline Case 4: PPS of the back and lower extremities & & \\
\hline
\end{tabular}

Fig. 2 Example of one item on the work-related functioning item list 
comment on the items separately. After discussing an item, the experts were asked for the last time to individually score any potential limitation of that particular item per case vignette. After the meeting, the researchers calculated the degree of consensus in this third round. This maximum of three rounds had been chosen for the modified Delhi study beforehand, for practical reasons. Consequently, the result after three rounds was the final result for the items that did not reach consensus.

\section{Results}

Three out of 18 invited experts declined to participate in the study due to time constraints, or lack of familiarity with the FAL or Delphi technique. The 15 participating experts reported that they provided health care for at least 40 patients with PPS each year. All 15 experts responded to the first and second email rounds. Thirteen experts attended the meeting in the third round and completed the last scoring round during the meeting. The other two experts completed the third scoring round by email with input from the expert comments derived from the meeting.

\section{First and Second Rounds}

In the first round, all experts scored the 78 items regarding limitations to work-related functioning in the four case vignettes individually. In 17 out of the 78 items, they reached consensus for all cases; these items were accepted and were not re-submitted in the next round to the experts. The experts reached consensus on 49 items for one, two or three of the cases; for 12 items they did not reach consensus in any of the cases (Table 1). All experts gave comments related to a particular item. The most frequently reported comment was the experienced difficulty in assessing the functional ability on a case vignette. The experts from curative health care experienced some difficulty in working with the items of the FAL, as they were not familiar with it. The experts with an insurance medicine background experienced difficulty accepting any limitation when no objective health problem was established. Based on these issues raised by the experts, 21 items divided over the four case vignettes were not fully assessed in this first round by one or two experts. After the second email round, there was an increase of consensus among the experts from 17 to 33 out of the 78 items for all cases. Most consensus in the cases was seen for necessary adjustments to the work environment (Table 1). A summary of the full process, rating options and results is provided in Appendix B.

\section{Meeting Discussion}

In the third round, during a meeting that lasted $3 \mathrm{~h}, 45$ items divided over the four case vignettes were discussed. During the meeting, the comments from the experts were mostly related to the exact interpretation of a particular item, and to the translation of the provided information about medical complaints in the case vignettes to the level of limitations to work-related functioning. Several items required a more extensive discussion, which lead to consensus among the experts in the majority of cases. No agreement could be reached for the category of limitations in working hours, as the experts continued to differ in their interpretation: the IPs of the social security agency commented that they had "to use strict rules in the assessment

Table 1 Number of items for which consensus on the level of limitations was reached, categorized per number of cases, per item category and per round

\begin{tabular}{|c|c|c|c|c|c|c|c|c|c|c|c|c|c|}
\hline \multirow[t]{3}{*}{ Category of items } & \multirow{3}{*}{$\begin{array}{l}\text { Total } \\
\text { items }\end{array}$} & \multicolumn{12}{|c|}{ Number of items with consensus, per number of cases (C) } \\
\hline & & \multicolumn{4}{|c|}{ Round 1} & \multicolumn{4}{|c|}{ Round 2} & \multicolumn{4}{|c|}{ Round 3} \\
\hline & & $\begin{array}{l}\text { One } \\
\text { (C) }\end{array}$ & $\begin{array}{l}\text { Two } \\
\text { (C) }\end{array}$ & $\begin{array}{l}\text { Three } \\
\text { (C) }\end{array}$ & $\begin{array}{l}\text { Four } \\
\text { (C) }\end{array}$ & $\begin{array}{l}\text { One } \\
\text { (C) }\end{array}$ & $\begin{array}{l}\text { Two } \\
\text { (C) }\end{array}$ & $\begin{array}{l}\text { Three } \\
\text { (C) }\end{array}$ & $\begin{array}{l}\text { Four } \\
\text { (C) }\end{array}$ & $\begin{array}{l}\text { One } \\
\text { (c) }\end{array}$ & $\begin{array}{l}\text { Two } \\
\text { (C) }\end{array}$ & $\begin{array}{l}\text { Three } \\
\text { (C) }\end{array}$ & $\begin{array}{l}\text { Four } \\
\text { (C) }\end{array}$ \\
\hline Personal functioning & 14 & 5 & 2 & 4 & 2 & 1 & 3 & 4 & 5 & 0 & 0 & 6 & 8 \\
\hline Social functioning & 12 & 3 & 1 & 7 & 1 & 0 & 2 & 5 & 5 & 0 & 0 & 2 & 10 \\
\hline Dynamic movements & 29 & 2 & 3 & 11 & 8 & 2 & 7 & 8 & 12 & 0 & 4 & 9 & 16 \\
\hline Static postures & 9 & 0 & 3 & 3 & 1 & 1 & 1 & 3 & 3 & 1 & 0 & 2 & 6 \\
\hline $\begin{array}{l}\text { Adjusting to } \\
\text { environment }\end{array}$ & 8 & 0 & 2 & 3 & 3 & 0 & 0 & 2 & 6 & 0 & 0 & 1 & 7 \\
\hline $\begin{array}{l}\text { Working hours and } \\
\text { time }\end{array}$ & 6 & 0 & 0 & 0 & 2 & 1 & 0 & 1 & 2 & 1 & 0 & 1 & 2 \\
\hline Total & 78 & 10 & 11 & 28 & 17 & 5 & 13 & 23 & 33 & 2 & 4 & 21 & 49 \\
\hline
\end{tabular}


of working hours limitations" [43], whereas all other physicians stated that "limitations in working hours can be used as a treatment, and as a tool in the return-to-work process and participation." All experts agreed that return to work could be reached for the presented case vignettes, if the patients received proper therapy and would be provided with a healthy work environment.

\section{Consensus on Limitations to Work-Related Functioning}

After the three modified Delphi rounds, the experts reached consensus on 49 out of 78 items $(63 \%)$ for the level of limitations to work-related functioning in all four cases. The experts did not reach consensus on any of the cases for two items that were related to the category of working hours (Table 1). The experts did reach consensus on the level of limitations to work-related functioning in 68 items (87\%) for PPS of the head, on 65 items (83\%) for PPS of the neck and upper extremities, on 72 items (92\%) for PPS of the abdomen and/or genitals, and on 64 items (82\%) on PPS of the back and lower extremities (Table 2). For the items on which the experts did reach consensus, the most frequent and the most severe limitations were found on PPS of the back and lower extremities, especially in the categories dynamic movements and static postures. For PPS of the head, the experts mostly agreed on limitations in the categories of personal and social functioning. For PPS of the abdomen and/or genitals, the experts agreed that limitations to work-related functioning would be likely for only three items. Most limitations for PPS of the neck and upper extremities were found to dynamic movements and static postures (Table 3). Appendix B lists all the items per case vignette, the level of consensus between the experts, and the degree of limitations that can be scored.

\section{Discussion}

The main purpose of this modified Delphi study was to obtain consensus on the level of limitations in work-related functioning for workers with Persistent "medically unexplained" physical symptoms (PPS). Fifteen physicians from five different medical specialties scored the level of limitations in 78 items, based on the functional ability list (FAL) and the international classification of functioning (ICF), for four different cases of PPS. After three rounds, they obtained consensus on the level of limitations for 49 items in all four cases. The level of limitations for PPS ranged between no limitations to severe limitations, and the number and severity of limitations differed between the four PPS cases. The physicians reported the highest number and most severe limitations for PPS of the back and lower extremities, whereas they reported hardly any limitations for PPS of the abdomen and/or genitals. They reported mainly limitations in personal and social functioning for PPS of the head, and mainly limitations in dynamic movements and static postures for PPS of the back and lower extremities as well as for PPS of the neck and upper extremities. The experts did not reach consensus for any of the cases on limitations of working hours.

\section{Comparison with Literature}

The literature on the assessment of work functioning for people with PPS is limited. As far as we know, no comparable study exists that has developed consensus-based recommendations concerning limitations to work-related functioning regarding PPS. However, previous studies have shown that for structuring functional limitations, the ICF is a useful framework for several health conditions comparable with PPS [39-41], such as chronic pain, dizziness and

Table 2 Number of items for which consensus on the level of limitations was reached after the third round, categorized per case and item category

\begin{tabular}{|c|c|c|c|c|c|}
\hline Category of items & $\begin{array}{l}\text { Total } \\
\text { items }\end{array}$ & $\begin{array}{l}\text { PPS of the } \\
\text { head }\end{array}$ & $\begin{array}{l}\text { PPS of the neck and upper } \\
\text { extremities }\end{array}$ & $\begin{array}{l}\text { PPS of the abdomen and/or } \\
\text { genitals }\end{array}$ & $\begin{array}{l}\text { PPS of the back and lower } \\
\text { extremities }\end{array}$ \\
\hline $\begin{array}{l}\text { Personal } \\
\text { functioning }\end{array}$ & 14 & 11 & 13 & 14 & 12 \\
\hline Social functioning & 12 & 10 & 12 & 12 & 12 \\
\hline $\begin{array}{l}\text { Dynamic } \\
\text { movements }\end{array}$ & 29 & 28 & 22 & 26 & 23 \\
\hline Static postures & 9 & 8 & 7 & 9 & 7 \\
\hline $\begin{array}{l}\text { Adjusting to } \\
\text { environment }\end{array}$ & 8 & 8 & 8 & 8 & 7 \\
\hline $\begin{array}{l}\text { Working hours and } \\
\text { time }\end{array}$ & 6 & 3 & 3 & 3 & 3 \\
\hline Total & 78 & 68 & 65 & 72 & 64 \\
\hline
\end{tabular}

PPS persistent "medically unexplained" physical symptoms 
Table 3 Level of limitations for which consensus was reached after the third round, categorized per case vignette and item category

\begin{tabular}{|c|c|c|c|}
\hline \multicolumn{2}{|l|}{ PPS of the back and lower extremities } & \multicolumn{2}{|l|}{ PPS of the head } \\
\hline Items per category (possible limitations) & $\begin{array}{l}\text { Level of } \\
\text { limitation }\end{array}$ & Items per category (possible limitations) & $\begin{array}{l}\text { Level of } \\
\text { limitation }\end{array}$ \\
\hline Personal functioning & & Personal functioning & \\
\hline High working tempo on the working place (2) & $1^{\mathrm{a}}$ & Focusing attention (3) & 1 \\
\hline Increased personal risk on the working place (2) & 1 & Solving problems (3) & 1 \\
\hline Dynamic movements & & Handling stress and other psychological demand (2) & 1 \\
\hline Pulling or pushing (3) & $2^{\mathrm{b}}$ & Distraction from others during work (2) & 1 \\
\hline Lifting (4) & 2 & Need for predictable working situation (2) & 1 \\
\hline Handle heavy objects frequently (2) & 1 & Frequent disruptions on the working place (2) & 1 \\
\hline Turning/twisting round (2) & 1 & Frequent deadlines and/or production peaks (2) & 1 \\
\hline Kneeling or squatting (2) & 1 & High working tempo on the working place (2) & 1 \\
\hline Walking time per day on work (4) & 2 & Social functioning & \\
\hline Walking on different surfaces (2) & 1 & Dealing with conflicts (3) & 1 \\
\hline Walking stairs (4) & 2 & Cooperating with someone else (3) & 1 \\
\hline Moving around using transportation (3) & 1 & Contact with clients (2) & 1 \\
\hline Static postures & & Management tasks (2) & 1 \\
\hline Maintaining a sitting position (4) & 2 & Dynamic movements & \\
\hline Maintaining a standing position (4) & 2 & Duration time of using a keyboard and/or mouse (4) & 1 \\
\hline Maintaining a kneeling or squatting position (2) & 1 & Adjusting to environment & \\
\hline Maintaining a bending or twisting position (2) & 1 & Sound intensity (2) & 1 \\
\hline Need for possibility to change body position (2) & 1 & Vibration (2) & 1 \\
\hline Adjusting to environment & & Working hours and working time & \\
\hline Wearing protection gear (2) & 1 & $\begin{array}{l}\text { Working during the night (between 00:00-06:00) } \\
\text { (2) }\end{array}$ & 1 \\
\hline Vibration (2) & 1 & & \\
\hline $\begin{array}{l}\text { PPS of the neck and upper extremities } \\
\text { Items per category (possible limitations) }\end{array}$ & Level of limitation & $\begin{array}{l}\text { PPS of the abdomen and/or genitals } \\
\text { Items per category (possible limitations) }\end{array}$ & Level of limitation \\
\hline Dynamic movements & & Static postures & \\
\hline Turning or twisting hands or arms (2) & 1 & Standing time per day on work (4) & 1 \\
\hline Reaching out (3) & 1 & Adjusting to environment & \\
\hline Pulling or pushing (3) & 1 & Vibration (2) & 1 \\
\hline Handle heavy objects frequently (2) & 1 & Possibility to use a toilet quickly (2) & 1 \\
\hline Climbing (4) & 1 & & \\
\hline \multicolumn{4}{|l|}{ Static postures } \\
\hline Working above shoulders (2) & 1 & & \\
\hline Maintaining head in one position (4) & 1 & & \\
\hline \multicolumn{4}{|l|}{ Adjusting to environment } \\
\hline Wearing protection gear (2) & 1 & & \\
\hline Vibration (2) & 1 & & \\
\hline
\end{tabular}

PPS persistent "medically unexplained" physical symptoms

a Mild limitations

b Moderate limitations

low back pain. For each of these conditions, a list of core items is available that describes possible limitations in bodily functions and structures. These lists address global core sets of limitations in activities, restrictions in participation and problems in environmental factors, which are essential for daily functioning. These core sets show similarities with the limitations we found in our study on dynamic movements, static postures, personal and social functioning, and environmental factors [39-41], and can be used to structure the limitations in work-related functioning 
on heading points. However, in comparison with our study, they are less suitable for describing and translating the precise work-related functioning [44].

Moreover, in agreement with the ICF core sets for the conditions that are comparable with PPS [39-41], our study showed, that in the assessment of work-related functioning, the different types of complaints have to be evaluated distinctly. Limitations to work-related functioning depend on the type and severity of the complaints and not on the underlying cause of the complaints, which is in contrast to other studies $[45,46]$.

We are not aware of any comparable studies that have developed similar recommendations for the assessment or structure of limitations in working hours for people with PPS. However, there are studies that have reported that people with PPS are able to work and participate if they are able to reduce their working hours [47], that a temporary reduction in working hours may contribute to the return-towork process, and that it may sometimes be a better alternative than full-time sick leave [48, 49]. In addition, a reduction in working hours can be seen as part of the treatment for PPS from a curative perspective [50]. On the other hand, in many European countries a limitation of working hours provides legal ground for a work disability benefit from an insurance perspective [27, 43]. This may lead to differences in views between physicians regarding advice concerning limitations in working hours. In daily practice, this may cause conflicting advice for patients with PPS [27].

\section{Strength and Limitations}

We believe our study had several strengths. The main strength of this study was the use of a modified Delphi technique among expert physicians of different specialties to reach consensus on limitations to work-related functioning for this difficult patient group. The broad range of medical expertise provided a wide range of competences and views that helped to maintain a broad perspective on the topic. The experts all had significant scientific credibility and/or working experience with PPS in their own specialty field. Moreover, they are representatives of their specialty field, and can therefore help improve the practical applicability of the outcomes of this study and facilitate the communication between different medical doctors. Another strength of this modified Delphi study was that all experts were provided with a summary of the relevant and available literature on this topic, and they were all able to give and revise their opinions and rates anonymously, without peer pressure. During the group discussion, they were able to discuss and elucidate their point of view. With strictly coordinated guidance from the process leader, we also tried to limit the risk of peer pressure during this discussion, however this could not be completely ruled out. Further strengths include that all participating physicians completed the entire study, and that they reached consensus on more than half of the items.

There are some weaknesses to consider when using a modified Delphi method. Firstly, the results of this study were based on the opinions of a small group of medical experts of five medical specialties. This may not be fully representative of all health care physicians. However, this is inevitable when using a qualitative approach, and using a limited number of participants was essential to having a structured meeting to reach consensus [33]. Secondly, the use of four case vignettes from the insurance medicine field as a guideline for the experts to score the limitations may also have some disadvantages, as case vignettes do not take into account co-morbidities, other medical or non-medical factors, or the information from a real medical consultation. However, case vignettes have been shown to be valuable and practical in a qualitative study such as ours [35].

Another limitation could be the use of the ICF in combination with the FAL, as not all experts were familiar with this method. The ICF is a validated list for the evaluation of functioning, and the FAL template has proven to be valuable for the assessment of functional work disabilities in the Netherlands [20, 38]. The FAL is not evidencebased, but the combination with the validated ICF makes it suitable for the purpose of this study and applicable for other European countries. IPs of the Dutch Social Security Agency have used the FAL for many years, and they therefore have much experience with using this assessment method. The other medical experts, however, were less familiar with this method, which we tried to overcome by providing full descriptions of the meanings on the items, functioning and limitations. Still, due to this knowledge lag not all items were scored by all experts in the study, which was solved in the next round with some extra information and explanation.

\section{Interpretation of the Results}

This study indicates that, despite a small body of evidence, physicians from several medical specialties were able to reach agreement for a substantial number of limitations to work-related functioning in PPS. This deepened the insight that people with PPS can have functional limitations despite the absence of objective medical findings. On the other hand, people with PPS still have many possibilities to work functioning despite these limitations, and this study indicates that the assessment of functioning seems to be based more on the specific impairment than on the disease. Although the presented cases were all considered PPS, there was a difference in the number and severity of 
limitations between them, and there was also a difference in the translation from medical findings and health complaints into functional abilities and disabilities in work between the different cases of PPS. We suggest that physicians have to keep this in mind in the assessment of functional work limitations.

\section{Implications for Practice and Future Research}

This was a first attempt to translate thoughts of physicians from different medical specialty fields to recommendations for work-related functioning related to PPS. The items in the list that reached consensus may be used in the daily practice of assessing work ability for people with PPS. This stimulates better inter-rater reliability and less conflicting advice, that may give patients with PPS a better understanding about their possibilities and work abilities. Implementing these recommendations may help the returnto-work process in the daily practice of disability assessments in the Netherlands. However, these recommendations may also be well applicable in other European countries as the issues regarding work disability in case of persistent physical symptoms are quite similar [22-26]. Besides, the insight that people with these symptoms can have functional limitations despite the absence of objective medical findings can give countries, in which people with these type of symptoms are not eligible for a disability benefit, thoughts to reconsider. As the emphasis in this study was on the items of the FAL, future studies need to assess to what extent these findings can be easily translated and are also applicable to all relevant items of the ICF.

Even though the experts reached consensus on more than half of the items in this study, there were still some items that they did not reach agreement on, especially in the category limitations in working hours. To deal with this difference in views, and to further improve inter-rater reliability, it is important to achieve further agreement among physicians, and to study the effectiveness of a temporary or permanent limitation in working hours.

\section{Conclusion}

For four different types of PPS, physicians of five different medical specialty fields reached consensus on 49 out of 78 items on the level of limitations to work-related functioning. The physicians agreed on how to translate the health complaints of people with different cases of PPS to limitations to work-related functioning. Different cases of PPS gave different outcomes on the level of limitations to workrelated functioning. Both the highest number and the most severe limitations were considered for symptoms of the back and lower extremities, especially in the dynamic and static movements categories. This means that the translation of PPS into functional limitations for work differs between different types of PPS and indicates that the assessment of functioning seems to be based more on the specific impairment than on the disease.

Funding This study was funded by the Dutch Social Security Agency (Funding Number 2002045). The funding organization had no further role in analysis and interpretation of the data, in writing the paper and in the decision to submit the paper for publication.

\section{Compliance with Ethical Standards}

Conflict of interest Author K. H. N. Weerdesteijn is employee of the Dutch Social Security Agency. Author J. R. Anema is shareholder of the VUmc spin-off company Evalua Nederland B.V. (www.evalua.nl) and holds a chair in Insurance Medicine on behalf of the Dutch Social Security Agency. Author A. J. van der Beek is shareholder of the VUmc spin-off company Evalua Nederland B.V. (www.evalua.nl). All authors declare that they have no conflict of interest in the analysis and interpretation of the data, in writing the paper and in the decision to submit the paper for publication.

Ethical Approval The Medical Ethics Committee of the VU University Medical Center (Amsterdam, The Netherlands) gave Ethical approval for the study. The same committee declared that no comprehensive ethical review was needed for this qualitative study. Though, all procedures performed in this study were in accordance with the ethical standards of this institutional research committee and with the 1964 Helsinki declaration and its later amendments or comparable ethical standards.

Informed Consent Informed consent was obtained from all individual participants included in the study.

Open Access This article is distributed under the terms of the Creative Commons Attribution 4.0 International License (http://crea tivecommons.org/licenses/by/4.0/), which permits unrestricted use, distribution, and reproduction in any medium, provided you give appropriate credit to the original author(s) and the source, provide a link to the Creative Commons license, and indicate if changes were made.

\section{References}

1. Morton LK, Elliott A, Cleland J, Deary V, Burton C. A taxonomy of explanations in a general practitioner clinic for patients with persistent "medically unexplained" physical symptoms. Patient Educ Couns. 2016; doi:10.1016/j.pec.2016.08.015.

2. Marks EM, Hunter MS. Medically unexplained symptoms: an acceptable term. Br J Pain. 2015;9(2):109-14.

3. Picariello F, Ali S, Moss-Morris R, Chalder T. The most popular terms for medically unexplained symptoms: the views of CFS patients. J Psychosom Res. 2015;78:420-6.

4. Nimnuan C, Hotopf M, Wessely S. Medically unexplained symptoms: an epidemiological study in seven specialities. J Psychosom Res. 2001;51(1):361-7.

5. Steinbrecher N, Koerber S, Frieser D, Hiller W. The prevalence of medically unexplained symptoms in primary care. Psychosomatics. 2011;52(3):263-71.

6. Jackson JL, Passamonti M. The outcomes among patients presenting in primary care with a physical symptom at 5 years. J Gen Intern Med. 2005;20(11):1032-7. 
7. Khan AA, Khan A, Harezlak J, Tu W, Kroenke K. Somatic symptoms in primary care: etiology and outcome. Psychosomatics. 2003;44(6):471-8.

8. Harris AM, Orav EJ, Bates DW, Barsky AJ. Somatization increases disability independent of comorbidity. J Gen Intern Med. 2009;24(2):155-61.

9. Loengaard K, Bjorner JB, Fink PK, Burr H, Rugulies R. Medically unexplained symptoms and the risk of loss of labor market participation-a prospective study in the Danish population. BMC Public Health. 2015;15:844.

10. Knudsen AK, Henderson M, Harvey SB, Chalder T. Long-term sickness absence among patients with chronic fatigue syndrome. Br J Psychiatry. 2011;199(5):430-1.

11. Hoedeman R, Blankenstein AH, Krol B, Koopmans PC, Groothoff JW. The contribution of high levels of somatic symptom severity to sickness absence duration, disability and discharge. J Occup Rehabil. 2010;20(2):264-73.

12. Norrmen G, Svardsudd K, Andersson DK. How primary health care physicians make sick listing decisions: the impact of medical factors and functioning. BMC Fam Pract. 2008;9:3.

13. Roelen CA, Koopmans PC, Groothoff JW. Subjective health complaints in relation to sickness absence. Work. 2010;37(1):15-21.

14. Rask MT, Rosendal M, Fenger-Gron M, Bro F, Ornbol E, Fink P. Sick leave and work disability in primary care patients with recent-onset multiple medically unexplained symptoms and persistent somatoform disorders: a 10-year follow-up of the FIP study. Gen Hosp Psychiatry. 2015;37(1):53-9.

15. Stenager EN, Svendsen MA, Stenager E. Disability retirement pension for patients with syndrome diagnoses. A registry study on the basis of data from the Social Appeal Board. Ugeskr Laeger. 2003;165(5):469-74

16. Schwegler U, Anner J, Boldt C, Glassel A, Lay V, De Boer WE, et al. Aspects of functioning and environmental factors in medical work capacity evaluations of persons with chronic widespread pain and low back pain can be represented by a combination of applicable ICF Core Sets. BMC Public Health. 2012;12:1088.

17. Anner J, Kunz R, Boer W. Reporting about disability evaluation in European countries. Disabil Rehabil. 2014;36(10):848-54.

18. Robinson JP, Turk DC, Loeser JD. Pain, impairment, and disability in the AMA guides. J Law Med Ethics. 2004;32(2):315-26.

19. Krohne K, Brage S. How GPs in Norway conceptualise functional ability: a focus group study. $\mathrm{Br} \mathrm{J}$ Gen Pract. 2008;58(557):850-5.

20. Stucki G. International Classification of Functioning, Disability, and Health (ICF): a promising framework and classification for rehabilitation medicine. Am J Phys Med Rehabil. 2005;84(10):733-40.

21. Anema JR, Van Der Giezen AM, Buijs PC. Ineffective disability management by doctors is an obstacle for return-to-work: a cohort study on low back pain patients sicklisted for 3-4 months. Occup Environ Med. 2002;59(11):729-33.

22. Elms J, O’Hara R, Pickvance S, Fishwick D, Hazell M, Frank T, et al. The perceptions of occupational health in primary care. Occup Med (Lond). 2005;55(7):523-7.

23. Swartling MS, Alexanderson KA, Wahlstrom RA. Barriers to good sickness certification-an interview study with Swedish general practitioners. Scand J Public Health. 2008;36(4):408-14.

24. Asbring P, Narvanen AL. Ideal versus reality: physicians perspectives on patients with chronic fatigue syndrome (CFS) and fibromyalgia. Soc Sci Med. 2003;57(4):711-20.

25. Nilsen S, Werner EL, Maeland S, Eriksen HR, Magnussen LH. Considerations made by the general practitioner when dealing with sick-listing of patients suffering from subjective and composite health complaints. Scand J Prim Health Care. 2011;29(1):7-12.
26. Amris K, Waehrens EE, Jespersen A, Bliddal H, DanneskioldSamsoe B. Observation-based assessment of functional ability in patients with chronic widespread pain: a cross-sectional study. Pain. 2011;152(11):2470-6.

27. Spanjer J. Urenbeperking bij SOLK: literatuuronderzoek. TBV. 2015;23:399-403.

28. Maeland S, Werner EL, Rosendal M, Jonsdottir IH, Magnussen LH, Lie SA, et al. Sick-leave decisions for patients with severe subjective health complaints presenting in primary care: a crosssectional study in Norway, Sweden, and Denmark. Scand J Prim Health Care. 2013;31(4):227-34.

29. Wind H, Gouttebarge V, Kuijer PP, Sluiter JK, Frings-Dresen $\mathrm{MH}$. The utility of functional capacity evaluation: the opinion of physicians and other experts in the field of return to work and disability claims. Int Arch Occup Environ Health. 2006;79(6):528-34.

30. Brage S, Donceel P, Falez F. Development of ICF core set for disability evaluation in social security. Disabil Rehabil. 2008;30(18):1392-6.

31. Hutchings A, Raine R, Sanderson C, Black N. A comparison of formal consensus methods used for developing clinical guidelines. J Health Serv Res Policy. 2006;11(4):218-24.

32. Jones J, Hunter D. Consensus methods for medical and health services research. BMJ. 1995;311:376-80.

33. Fink A, Kosecoff J, Chassin M, Brook RH. Consensus methods: characteristics and guidelines for use. Am J Public Health. 1984;74(9):979-83.

34. Cantrill JA, Sibbald B, Buetow S. Indicators of the appropriateness of long-term prescribing in general practice in the United Kingdom: consensus development, face and content validity, feasibility, and reliability. Qual Health Care. 1998;7(3):130-5.

35. Vonk NA, Huirne JA, Brolmann HA, van Mechelen W, Anema JR. Multidisciplinary convalescence recommendations after gynaecological surgery: a modified Delphi method among experts. BJOG. 2011;118(13):1557-67.

36. Aamland A, Malterud K, Werner EL. Patients with persistent medically unexplained physical symptoms: a descriptive study from Norwegian general practice. BMC Family Pract. 2014;15(107):1471-2296.

37. Dutch Social Security Agency. Annual statistical report on the Security Disability Insurance Program. 2012; http://www.uwv.nl/ overuwv/Images/UWV_Kennisverslag_2012-I\%20klik.pdf.

38. Dutch Social Security Agency. Functional Ability List: Functionele mogelijkheden en voorwaarden voor het verrichten van arbeid. The absenteeism database for professionals. 2002; http:// www.tracksoftware.n1/wp-content/uploads/2015/01/FML.pdf.

39. Cieza A, Stucki G, Weigl M, Kullmann L, Stoll T, Kamen L, et al. ICF Core Sets for chronic widespread pain. J Rehabil Med. 2004;44:63-8.

40. Cieza A, Stucki G, Weigl M, Disler P, Jackel W, van der Linden $\mathrm{S}$, et al. ICF Core Sets for low back pain. J Rehabil Med. 2004;44:69-74.

41. Grill E, Bronstein A, Furman J, Zee DS, Muller M. International Classification of Functioning, Disability and Health (ICF) Core Set for patients with vertigo, dizziness and balance disorders. J Vestib Res. 2012;22(5-6):261-71.

42. Board of health. Insurance physicians protocols: nonspecific low back pain, chronic fatigue syndrome, Whiplash associated disorder I/II, Chronic shoulder complaints. Dutch association for Insurance Physicians. 2008; http://www.nvvg.nl/Whiplash_Aspe cifieke_lage_rugklachten_en_Hartinfarct.pdf.

43. Spanjer J. Urenbeperking bij SOLK: mediprudentie en jurisprudentie. TBV. 2015;7:304-8.

44. Schult ML, Ekholm J. Agreement of a work-capacity assessment with the World Health Organisation International Classification 
of Functioning, Disability and Health pain sets and back-to-work predictors. Int J Rehabil Res. 2006;29(3):183-93.

45. Aaron LA, Buchwald D. A review of the evidence for overlap among unexplained clinical conditions. Ann Intern Med. 2001;134(9):868-81

46. Tavel ME. Somatic symptom disorders without known physical causes: one disease with many names? Am J Med. 2015;128(10):1054-8.

47. Henriksson CM, Liedberg GM, Gerdle B. Women with fibromyalgia: work and rehabilitation. Disabil Rehabil. 2005;27(12):685-94.

48. Viikari-Juntura E, Kausto J, Shiri R, Kaila-Kangas L, Takala EP, Karppinen J, et al. Return to work after early part-time sick leave due to musculoskeletal disorders: a randomized controlled trial. Scand J Work Environ Health. 2012;38(2):134-43.

49. Oyeflaten I, Midtgarden IJ, Maeland S, Eriksen HR, Magnussen LH. Functioning, coping and work status three years after participating in an interdisciplinary, occupational rehabilitation program. Scand J Public Health. 2014;42(5):425-33.

50. Shiri R, Kausto J, Martimo KP, Kaila-Kangas L, Takala EP, Viikari-Juntura E. Health-related effects of early part-time sick leave due to musculoskeletal disorders: a randomized controlled trial. Scand J Work Environ Health. 2013;39(1):37-45. 